\title{
Sales promotions and channel coordination
}

\author{
Berend Wierenga $\cdot$ Han Soethoudt
}

Received: 13 August 2008 / Accepted: 8 July 2009/Published online: 1 August 2009

(C) The Author(s) 2009. This article is published with open access at Springerlink.com

\begin{abstract}
Consumer sales promotions are usually the result of the decisions of two marketing channel parties, the manufacturer and the retailer. In making these decisions, each party normally follows its own interest: i.e. maximizes its own profit. Unfortunately, this results in a suboptimal outcome for the channel as a whole. Independent profit maximization by channel parties leads to a lack of channel coordination with the implication of leaving money on the table. This may well contribute to the notoriously low profitability of sales promotions. This paper first shows analytically why the suboptimality occurs, and then presents an empirical demonstration, using a unique dataset from an Efficient Consumer Response (ECR) project; ECR is a movement in which parties work together to optimize the distribution channel). In this dataset, actual profit is only a small fraction of potential profit, implying that there is a large degree of suboptimality. It is important that (1) channel parties are aware of this suboptimality; and (2) that they have tools to deal with it. Solutions to the channel coordination problem should ensure that the goals of the individual channel parties are aligned with the goals of the channel as a whole. The paper proposes one particular agreement for this purpose, called proportional discount sharing. Application to the ECR data shows a win-win
\end{abstract}

\footnotetext{
B. Wierenga $(\triangle)$

Rotterdam School of Management, Erasmus University, P.O. Box 1738, 3000 DR Rotterdam, Netherlands

e-mail: bwierenga@rsm.nl

H. Soethoudt

Agrotechnology and Food Innovations BV, P.O. Box 17, 6700 AA Wageningen, Netherlands e-mail: Han.soethoudt@wur.nl
}

result for both the manufacturer and the retailer. Recognition of the channel coordination problem by the manufacturer and the retailer is the necessary starting point for agreeing on a way of solving it in a win-win fashion.

Keywords Sales promotions · Price discounts · Channel coordination · Double marginalization - Efficient consumer response $\cdot$ Win-win agreement

\section{Introduction}

Sales promotions are instruments to stimulate the sales of products and brands, especially in consumer-packaged goods. Frequently, over $20 \%$ of the sales in a product category occur under sales promotions (Teunter 2002). The Trade Promotion Report, 2005, indicates that promotion accounted for roughly $75 \%$ of marketing expenditures for US packaged goods manufacturers between 1997 and 2004; the other $25 \%$ is advertising. In this way, trade promotions play an important role in the marketing of fast-moving consumer products.

The volume effects of sales promotions are mostly very evident, sometimes spectacularly so. Gross lift factors of five to ten are no exceptions (Blattberg et al. 1995). However, there are continuing doubts about the profitability of sales promotions. In a Supermarket News article in 1996, Orgel mentioned that only $10-20 \%$ of grocery promotions are profitable events. A more recent consultancy report about sales promotions carries the telling title, "Pouring Money into a Leaky Bucket" (Jones 2004). Academic researchers also express concerns, both about the profitability of sales promotions for the manufacturer (Achenbaum and Mitchel 1987; Ailawadi 2001; Farris and Ailawadi 1992; Nijs et al. 2001) and for the retailer (Urbany et al. 2000; Walzer 1987). 
Recent empirical studies confirm this bleak picture. Sales promotions account for approximately two-thirds of all promotional spending, but only $16 \%$ are profitable (Drèze and Bell 2003). Srinivasan et al.'s (2004) analysis of data for 75 brands in 25 categories over 399 weeks indicates that the overall channel gain from sales promotions is negative. Ailawadi et al. (2006) examine all the promotions in a whole year of the leading drug store CVS in the United States and find that the net profit impact is negative.

Why do channel parties continue to use sales promotions, if they are such "leaky buckets"? From a managerial perspective, there can be various motivations for sales promotions, even if they are not directly profitable, e.g. to increase market share (manufacturer), to boost store traffic (retailer), and strategic considerations (for example to maintain a good relationship with a favorite channel partner). Furthermore, there may be a prisoner dilemma situation: if everyone uses sales promotions, you have to follow suit, even if it is clear that it would be better to refrain from using them.

Whatever the motivation for sales promotions, their profitability should always be an important concern and this paper investigates how the profitability of sales promotions can be improved. We focus on one particular cause of the low profitability of sales promotions - the lack of channel coordination. A marketing channel is said to be coordinated if the decisions of the different actors result in the maximum profit for the channel (Jeuland and Shugan 1983; Ingene and Parry 2004). In the context of sales promotions, lack of channel coordination occurs when the combination of the independent decisions of the manufacturer and the retailer do not fully exploit the potential of the channel. This results in a channel profitability of sales promotions that is suboptimal. We explain this in more detail in "Analytical approach to double marginalization in sales promotions".

As shown in Fig. 1, two parties in the distribution channel decide about sales promotions, the manufacturer and the retailer. Their decisions affect the characteristics of a sales promotion, such as the type of sales promotion, the size of the price discount, announcements in flyers, pointof-sale displays, etc. These, in turn, determine the effect of the sales promotion in terms of extra sales. However, a sales promotion usually also involves extra costs (planning, logistics, sales promotion materials such as flyers and displays, etc.). The extra sales (and the margins on these sales) together with the costs determine the profitability of the sales promotion, for each of the channel parties separately, and for the channel as a whole.

Since the advent of scanner data there has been a surge in research on the measurement of sales promotion effects using econometric techniques. We now have a rich set of sophisticated models and methods (see Van Heerde and Neslin 2008 for a recent overview) to estimate the effects of sales promotions on sales (i.e., the link between the characteristics of the sales promotion and the extra sales in Fig. 1). However, these models only tell us what the extra sales will be, given the characteristics of the sales promotion. To explain the profitability of sales promotions (or the lack thereof), we also need to consider what drives the decisions of the channel parties, leading to the actual sales promotions that we observe in the market. In particular, it is important to examine possible forces that drive sales promotions in a direction that makes them less profitable than they could have been. Here we refer to the lack of channel coordination that is the central topic of our research. "Decisions on sales promotions in the distribution channel" discusses the nature and function of sales promotions, how the parties in the distribution channel determine their characteristics (especially the price discount), and how marketing channel theory can help to explain suboptimal sales promotions. "Analytical approach to double marginalization in sales promotions" analytically shows how the lack of channel coordination systematically leads to suboptimal sales promotions.

The empirical measurement of losses caused by the lack of channel coordination in practice is not easy because it requires information that channel parties normally do not

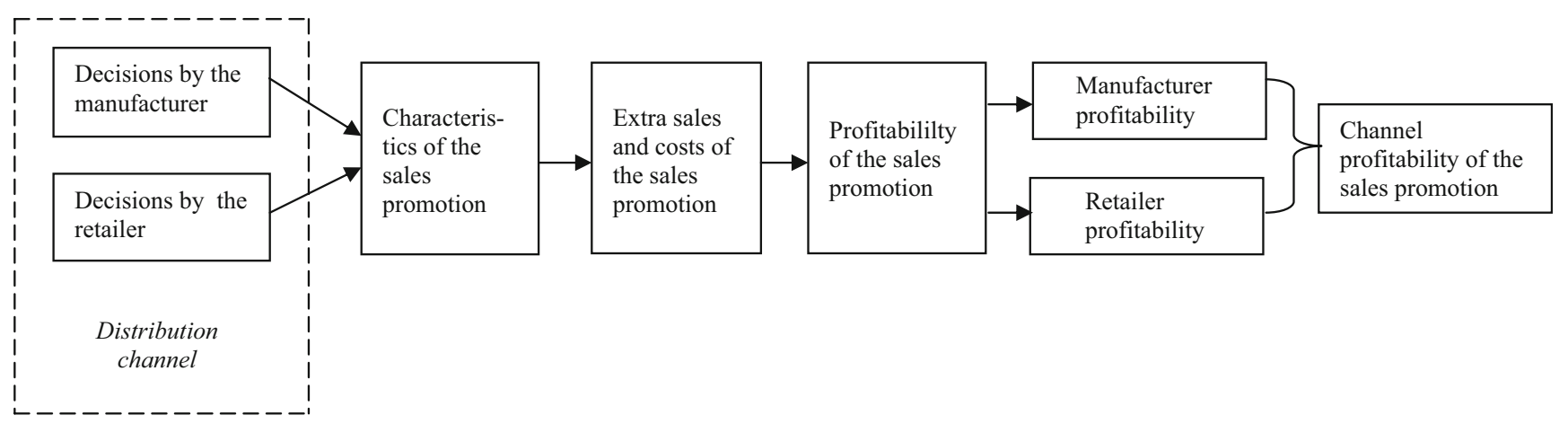

Fig. 1 How the decisions of the manufacturer and the retailer determine the profitability of a sales promotion. 
share. Especially information about the costs of sales promotions is mostly lacking. The present study uses a unique database from an ECR project, in which parties did exchange detailed information. In "The ECR study", we use this database and empirically demonstrate the existence of a lack of channel coordination for sales promotions, and demonstrate how serious its impact can be.

"Removing suboptimality by means of channel coordination" discusses possible solutions for the channel coordination problem and proposes a "proportional discount sharing agreement" (PDS) between the manufacturer and the retailer, in which each party contributes to the consumer price discount in proportion to its original margin. "Application of PDS to the ECR data" uses data from the ECR project to show the effect of the proportional discount sharing agreement for the manufacturer and the retailer. The managerial implications of PDS and recommendations for further research are discussed in the conclusion.

\section{Decisions on sales promotions in the distribution channel}

Sales promotions are "action-oriented marketing events whose purpose is to have a direct impact on the behavior of customers" (Blattberg and Neslin 1990, p 3). The most important features of sales promotions are: (i) inducement to enhance sales; (ii) non-routine; and (iii) short duration. The idea is that a temporary shift in stimuli causes a sudden shift in behavior (Van Waterschoot and van den Bulte 1992). The purpose of these temporary incentives is to "act now" (Rossiter and Bellman 2005, p 347). In the majority of sales promotions in fast-moving consumer goods, these incentives include a price discount for the consumer, mostly accompanied by displays on the shop floor, advertisements in leaflets and door-to-door local newspapers, and sometimes radio and/or TV commercials. This implies that a sales promotion usually involves several marketing mix elements: price, communication, product (e.g., special promotional packages) and place. Therefore, sales promotions may pervade all of the four Ps (Van Waterschoot and van den Bulte 1992).

As shown in Fig. 1, the characteristics of a sales promotion are the result of decisions made by the manufacturer and the retailer.

The relative influence of these two channel parties on the sales promotion and the contribution of each of the partners to the costs depend on the relative power of the parties (Kasulis et al. 1999). In the market described in this paper, large manufacturers deal with large supermarket chains. This means that in our case both parties are strong, implying a "strong symmetric situation" in the typology of Kasulis et al. (1999). These authors state that a strong symmetric situation leads to agreements such as calendar marketing schemes, display allowances, and cooperative advertising. All these elements are present in the setting of our study. In the European market studied in this paper, the influence of the retailer on sales promotions is relatively strong. It is the retailer who initiates the process by presenting an annual promotions plan. The retailer then invites manufacturers to propose sales promotions, that should fit in this plan. These proposals are first quite general (only the products and the weeks are determined), but as the time draws closer, they become more specific and include the discounts given by the manufacturer and the retailer (Verstappen et al. 1998). This situation may differ from North America, where the manufacturer mostly seems to be the initiator of a sales promotion (comment from one of the reviewers). The agreements on sharing the costs for displays and cooperative promotion are usually structural. However, for each individual sale promotion, each party decides what it is willing to contribute to the consumer price discount. The sum of these two elements, the manufacturer discount and the retailer discount, is the consumer discount. In this paper, we look at how these discounts come about - at the mechanism behind themand examine if and how this mechanism leads to a suboptimal outcome. Since sales promotions occur within the environment of the distribution channel, we start our discussion with distribution channel literature.

\section{Distribution channel literature}

Over the last 40 years, our understanding of distribution channels has greatly improved (Coughlan et al. 2006). Channel communication, power of channel members, the monitoring of channel members, channel control, channel conflict, and contracting between channel partners are examples of topics that have been studied in channel literature (Frazier 1999). Although sales promotions are related to most of these topics in some sense, this subject has not received much specific attention in marketing channel literature. An important sub-stream of this literature focuses on channel coordination, using a game-theory approach. Authors using this approach include Jeuland and Shugan (1983); McGuire and Staelin (1983); Choi (1991); and Ingene and Parry (2004, 2007). However, publications in this sub-stream do not appear to address sales promotions to any great degree. The element of price (i.e., price agreements between parties in the distribution channel) plays an important role in this work, but from our earlier discussion of sales promotions, it is clear that a sales promotion with a temporary price discount is different from a structural decrease in the consumer price. In the case of a sales promotion, consumers know that it is a temporary opportunity, and marketing communication activities such as displays, features and advertisements support the sales 
promotion. Therefore, the sales response elasticity is likely to be different for a sales promotion, as compared to a change in the regular price. This is also empirically confirmed in, for example, Guadagni and Little (1983) and Inman et al. (1990).

\section{Sales promotions literature}

As we already mentioned, sales promotions literature focuses on the measurement of the effects of sales promotions (Blattberg and Neslin 1990; Neslin 2002; Van Heerde and Neslin 2008). When sales promotions literature addresses the decisions of the actors, the typical approach is from the perspective of one of the actors. For example, researchers study how retailers react (or should react) to trade deals offered by manufacturers (Murry and Heide 1998; Tyagi 1999; Walters 1989). Also recent work on pass-through, see for example Besanko et al. (2005); Moorthy (2005), and Pauwels (2007), examines how retailers make decisions (or should make decisions), given the decision of the manufacturer This is a one-sided approach, lacking the perspective of channel optimization. In the context of forward buying, these authors show how manufacturers and retailers can make specific agreements that benefit both parties. Forward buying means that the retailer purchases more from the manufacturer at the sales promotion price than it will sell during the sales promotion. The retailer sells the rest later at the regular price. However, such agreements do not coordinate the channel for sales promotions. This is discussed in more detail in the next section.

We conclude that thus far, published sales promotions literature has overlooked the problem of lack of channel coordination (see also Ailawadi et al. 1999).

Link between channels literature and sales promotions literature

From the previous discussion, it is clear that the link between channels literature and sales promotions literature remains incomplete. In the former there is the important notion of channel coordination. The most important notion of channel coordination is the following; parties in the distribution channel make their decisions from the perspective of the benefits for their own organization. However, if a particular actor somewhere in the marketing channel makes a decision, this has implications for the sales and profits of other channel members. For example, if a retailer gives a price discount to its consumers, this will result in the selling of a larger volume. This does not only affect the retailer, but also the manufacturer who will sell more (to the retailer), and make more profit (assuming a positive profit). Therefore, the actions of one particular channel member affect the outcome for the channel beyond the outcomes for the actor itself. If parties act in their own (myopic) interest and do not recognize the extra effects for the channel, suboptimization of the channel as a whole will occur.

Jeuland and Shugan (1983) show that the lack of channel coordination is fundamental, and in principle applies to all marketing variables, price, as well as non-price variables (e.g. advertising and shelf-space decision). In this paper, we take the general notion of channel coordination and apply this to the specific topic of the sales promotion decisions of manufacturers and retailers. A lack of channel coordination results in lower channel profits, and therefore contributes to the low profitability of sales promotions observed in practice. The problem is solvable through a channel coordination mechanism (Jeuland and Shugan 1983) guaranteeing that individual channel members, when pursuing their own interest, also act in the interest of the channel as a whole. Channel coordination in its generic form has received considerable attention in economics and marketing, under the name of the "double marginalization problem" (Gerstner and Hess 1995; Jeuland and Shugan 1983; Spengler 1950). The term "double marginalization" derives from the fact that each channel member increases its efforts (i.e., increases its discount) up to the point that its own marginal revenue is equal to its own marginal costs. As we will see in the next section, if both channel members do this ("double marginalization"), the result is a suboptimal outcome at the channel level.

\section{Relevance of the insights}

This paper extends the general channel coordination theory to sales promotions. We will show that sales promotion agreements that coordinate the channel lead to higher profits. Although the extension is interesting, this will not come as a surprise to readers familiar with the theory of channel coordination since a coordinated channel always performs better than an uncoordinated channel. However, the degree of the improvement, as observed in the empirical study, is quite impressive. For readers of sales promotions literature, this paper explains how the double marginalization phenomenon contributes to the low profitability of sales promotions. For both groups, and for practitioners in the market place, the possibility of restoring channel coordination by means of a proportional discount sharing agreement is equally important.

\section{Analytical approach to double marginalization in sales promotions}

In this section, we apply the general channel coordination theory (Jeuland and Shugan 1983; Ingene and Parry 2004) to sales promotions. We derive expressions for the actual 
and optimal sales promotions as functions of the discounts given during the sales promotions. This section shows that if both the manufacturer and the retailer maximize their own profit, the sales promotions are suboptimal at the channel level. The intuitive reasoning for this is as follows: a channel member spending money to make a sales promotion more attractive for consumers (for example by giving a larger discount) not only increases its sales, but also the sales of the channel partner. For example, a larger discount given by the retailer also allows the manufacturer to sell more (and make more profit). However, when making the trade-off between costs and increased revenue, a channel member compares the costs of the sales promotion only with an increase in its own profit. Consequently, the channel member has no incentive to enhance the sales promotion beyond the point where the additional (own) costs become equal to the additional (own) revenue, i.e. where marginal revenue becomes equal to marginal costs. This neglects the additional revenue that the sales promotion generates elsewhere in the channel. From a channel point of view, an individual channel member stops enhancing a sales promotion too early in the process.

Consider the following demonstration. Whether or not a price discount is profitable at the channel level depends on the extra sales (volume) generated and the margin sacrificed on the regular sales (see also Dekimpe and Hanssens 1999). If and how each of the two parties, the retailer and the manufacturer, benefit from the sales promotion depends on the sharing of the burden of the consumer price discount, that is, how much each party contributes to this discount. The allocation of other costs in the sales promotion (displays in stores, advertisements in local newspapers and retailers' door-to-door leaflets) also affects the profitability of the sales promotion for each party.

Table 1 gives the definition of the variables in this paper.

Let $d_{m}$ be the contribution to the consumer price discount by the manufacturer, and $d_{r}$ the contribution of the retailer. The consumer price discount, $d_{c}$, is the sum of each party's contributions to the discount, that is,

$\mathrm{d}_{\mathrm{c}}=\mathrm{d}_{\mathrm{r}}+\mathrm{d}_{\mathrm{m}}$.

Now, if the manufacturer sets his discount, $d_{m}$, in such a way that its own profit is at its maximum, it can be shown (Appendix 1, Eq. A1.7) that its optimal discount is:

$\mathrm{d}_{\mathrm{m}} *=\left(\mathrm{s}-\mathrm{c}-\mathrm{d}_{\mathrm{r}}\right) / 2+\mathrm{B} /(2 \gamma)$

In the notation * refers to the optimal value if the channel party maximizes the own profit and ${ }^{* *}$ refers to the optimal value if the channel party maximizes the channel profit. Furthermore, $\mathrm{s}$ is the (regular) selling price of the manufacturer to the retailer, $\mathrm{c}$ is the manufacturing costs per unit, $B$ is the baseline sales, and $\gamma$ is the coefficient of $d_{c}$ in the discount response function. Equation 1 is the expression for a linear discount response function, but the results are true for any function where sales increase as discount becomes larger. (The results related to the effects of double marginalization hold for any upward-sloping discount response function which is equivalent to a downward-sloping demand function-, see Jeuland and Shugan (1983, p 242)).

By considering only its own profit, the manufacturer does not take into account that increasing its discount $d_{m}$, not only affects its own results, but also those of the retailer. After all, a larger $d_{m}$ implies a larger $d_{c}$, and therefore,

Table 1 Definitions of the variables used in the paper

\begin{tabular}{ll}
\hline$d_{m}$ & $=$ price discount given by the manufacturer \\
$d_{r}$ & $=$ price discount given by the retailer \\
$d_{c}$ & $=$ total price discount for the consumer $\left(d_{c}=d_{m}+d_{r}\right)$ \\
$p$ & $=$ regular consumer price \\
$p_{d}$ & $=$ consumer discount price $\left(p_{d}=p-d_{c}\right)$ \\
$q\left(p_{d}\right)$ & $=$ volume of the product sold (in units) as a function of the (discounted) consumer price \\
$s$ & $=$ selling price of the manufacturer to the retailer (regular, i.e., in the absence of sales promotions) \\
$c$ & $=$ manufacturing costs per unit (production costs) \\
B & $=$ baseline sales, i.e., the sales volume of the product in the absence of the sales promotion \\
$F_{r}$ & $=$ fixed costs of the retailer \\
$F_{m}$ & $=$ fixed costs of the manufacturer \\
$F_{\mathrm{r}}$ & $=$ fixed costs of the sales promotion for the retailer (planning and execution costs) \\
$\mathrm{FS}_{\mathrm{m}}$ & $=$ fixed costs of the sales promotion for the manufacturer (planning and execution costs) \\
$\Pi_{\mathrm{r}}$ & $=$ profit from the sales promotion for the retailer \\
$\Pi_{\mathrm{m}}$ & $=$ profit from the sales promotion for the manufacturer \\
$\Pi_{c}$ & $=$ profit from the sales promotion for the channel $\left(\Pi_{\mathrm{c}}=\Pi_{\mathrm{r}}+\Pi_{\mathrm{m}}\right)$ \\
\hline
\end{tabular}


higher (volume) sales of the retailer. This means that the retailer's profit is also larger (as long as the retailer's margin is positive). The manufacturer would take the additional profit of the retailer into account if it owned the retailer. In that case, it would set its discount (see Appendix 1, Eq. A1.8) at:

$\mathrm{d}_{\mathrm{m}}{ }^{* *}=\left(\mathrm{s}-\mathrm{c}-\mathrm{d}_{\mathrm{r}}\right) / 2+\mathrm{B} /(2 \gamma)+\left(\mathrm{p}-\mathrm{s}-\mathrm{d}_{\mathrm{r}}\right) / 2$

A comparison of Eq. (2) with Eq. (1) shows that the manufacturer's discount is larger if it maximizes overall channel profit (assuming that the retailer's margin [p - s $\mathrm{d}_{\mathrm{r}}$ ] is positive).

Therefore, a manufacturer maximizing its own profit sets the discount lower than when maximizing the profit of the channel.

For the retailer, a similar mechanism is at work. If the retailer maximizes its own profit, it sets its discount at (Appendix 1, Eq. A1.10):

$\mathrm{d}_{\mathrm{r}}{ }^{*}=\left(\mathrm{p}-\mathrm{s}-\mathrm{d}_{\mathrm{m}}\right) / 2+\mathrm{B} /(2 \gamma)$

However, if the retailer takes the profit effect for the manufacturer into account (which it would do if it owned the manufacturer) the optimal discount is (Appendix 1, Eq. A1.11):

$\mathrm{d}_{\mathrm{r}}{ }^{* *}=\left(\mathrm{p}-\mathrm{s}-\mathrm{d}_{\mathrm{m}}\right) / 2+\mathrm{B} /(2 \gamma)+\left(\mathrm{s}-\mathrm{c}-\mathrm{d}_{\mathrm{m}}\right) / 2$

The discount is lower as long as the manufacturer makes a positive margin $\left[\mathrm{s}-\mathrm{c}-\mathrm{d}_{\mathrm{m}}\right]$.

Therefore, each channel party, the manufacturer and the retailer, sets its discount in a way that the own marginal profit $\left(\delta \Pi_{\mathrm{m}} / \delta \mathrm{d}_{\mathrm{m}}\right.$ and $\delta \Pi_{\mathrm{r}} / \delta \mathrm{d}_{\mathrm{r}}$, respectively) equals zero (double marginalization).

Abstracting from the individual channel parties (manufacturer and retailer) we can also derive the optimal channel discount directly (see Appendix 1, Eq. A1.14):

$\mathrm{d}_{\mathrm{c}}{ }^{* *}=(\mathrm{p}-\mathrm{c}) / 2+\mathrm{B} /(2 \gamma)$

Going back to the situation of the manufacturer owning the retailer, the total consumer discount would be: $d_{m}{ }^{* *}+d_{r}$, and using Eq. (1) this is:

$\mathrm{d}_{\mathrm{m}} * *+\mathrm{d}_{\mathrm{r}}=(\mathrm{p}-\mathrm{c}) / 2+\mathrm{B} /(2 \gamma$

It is clear from Eq. (5) that this is equal to $d_{c}{ }^{* *}$, i.e. the channel-optimal discount.

In the same way, if the retailer owned the manufacturer:

$\mathrm{d}_{\mathrm{r}} * *+\mathrm{d}_{\mathrm{m}}=(\mathrm{p}-\mathrm{c}) / 2+\mathrm{B} /(2 \gamma)=\mathrm{d}_{\mathrm{c}} * *$.

It is apparent that if a channel member sets its discount to maximize the profit of both parties, it automatically maximizes the channel profit. However, channel members typically only maximize their own profit, which leads to discounts that are too low and therefore suboptimal from the channel point-of-view. The implication of this myopic approach is that the joint profits are lower than would have been possible.

Comments to this modeling approach

We add two comments. First, we use a single-period bilateral monopoly model and look at the coordination problem within the "channel dyad" of one manufacturer and one retailer (Ingene and Parry 2004, 2007). In principle, we have a vertical Nash game here. If such a game were "played out" completely, this would lead to equilibrium values for the manufacturer discount and the retailer discount, known as the Nash equilibrium. We give the expressions for the Nash equilibrium values in Appendix 1 (Eqs. A1.17, A1.18). We will check empirically in our database to what extent a Nash equilibrium occurs.

Second, we look at dyadic-coordination between one manufacturer and one retailer and we abstract from other retailers and manufacturers. This is reasonable in the empirical setting of the Netherlands, where each sales promotion is unique, with conditions separately negotiated between the manufacturer and the retailer within the dyad. Retailers work with "promotion calendars" and generally there is no other sales promotion in the same product (sub) category in the same week. Furthermore, the same product of a manufacturer is usually not in a sales promotion at another retailer in the same week. Nevertheless, even if the presence of other parties would be a reason for a less than channel-optimal sales promotion within a particular dyad, it is still important to know how much is lost by departing from the sales promotion that would have been the best for the particular dyad. In that case, the analysis at the level of the dyad remains important.

After this formal analytical approach, we now turn to the ECR study to see how this works in practice.

\section{The ECR study}

The data used comprise 86 sales promotions in a food product category, collected in the context of an ECR project. As mentioned earlier, Efficient Consumer Response is a movement in which manufacturers and retailers work together in order to optimize the distribution channel (FMI 1993; Coughlan et al. 2006). "Efficient sales promotions" is one of the four major ECR domains for improving the cooperation between manufacturers and retailers (FMI 1993)

The dataset for each sales promotion contains the actual price discount, the sales volume generated at this discount, and the contributions of each channel partner to the discount. Furthermore, in the ECR project there is information about manufacturing costs, handling and 
execution costs of sales promotions, the costs of features and display materials, and about the payments made by the manufacturer to the retailer to compensate for sales promotions costs. With this detailed information, we can compute actual profitability, including the division of profit between manufacturer and retailer. Therefore, we can determine the amount of suboptimality: the extent to which the channel parties have acted in a suboptimal way and have left money on the table.

\section{The data}

The 86 sales promotions in the dataset cover a period of 23 weeks and are from a retailing chain in the Netherlands. The (overall) product category is fresh dessert products with six subcategories: yogurt, sweet desserts, drinks, functional foods, curd, and culinary. The actual sales promotions take place within one of these subcategories. The database includes all sales promotions in the retail chain in the six subcategories of the fresh desserts category during the period studied. All promotions are price discounts, supported by feature advertisements in door-todoor circulars distributed around the stores. The sales data are scanner data collected by the retailer.

The running time of these sales promotions is 1 week. All relevant information is available: regular consumer price, price discount given to the consumer, regular purchasing price for the retailer, and purchasing price for the retailer during discount. In the ECR project for the product category that we study, the production costs of the manufacturer on average account for $70 \%$ of the regular purchasing price of the retailer ("selling price" in Table 1). We use this figure for the sales promotions in our data set. (Often companies do not know exact production costs figures and then work with similar assumptions). However, we have exact figures for the specific products for 25 of the 86 sales promotions involved in our study and we also carry out a separate computation of the profit increase from the actual to the channel-optimal consumer discount for these 25 .

We also take into account the processing costs of the sales promotions. For an individual sales promotion these are "fixed costs", independent of the sales volume generated by the sales promotion. We use the results from an Activity Based Costing project (Verstappen et al. 1998) for the processing costs (at the manufacturer and the retailer). These authors first defined all activities carried out for a sales promotion at the retailer and the manufacturer and then measured the resources spent on these activities (e.g., time, budget, space) during a particular period. Examples of such activities are planning, writing a proposal, logistic activities of storing and transportation, production of leaflets, filling displays, costs of space, etc. The fixed costs per sales promotion is calculated by dividing the number of sales promotions during the same period. Cost figures for the out-of-pocket cost of advertisements and leaflets are directly available. It turns out that the retailer incurs the bulk ( $96 \%$ ) of the actual costs of the sales promotions. However, since the manufacturer pays the retailer an amount for each sales promotion, in the end the manufacturer on average pays $72 \%$ of the fixed costs.

For the sales promotions in the database, the regular consumer price of the items ranges from NLG 0.69 cents to NLG 4.99. The average discount is NLG 0.37 cents or $18 \%$ of the average regular consumer price of NLG 2.08. In this paper, we work with the monetary unit (Netherlands guilders-NLG) that was applicable at the time to which the data refer ( 1 NLG is about 0.45 Euro or 0.60 US\$). Data shows that the retailer has paid (on average) $70 \%$ of the price discount for the promotions in the database. This large share in the consumer discount means that the retailer does not simply pass on the manufacturer's discount to the consumer but "amplifies" it. The mean "pass-through" equals (Bucklin 1987) $1 /(1-0.70)^{*} 100=333$. In the literature, the figures for pass-through vary widely. One earlier study, Chevalier and Curhan (1976), found passthrough rates ranging from 0 to $211 \%$. Armstrong (1991) reported pass-through rates for four product categories in FMCG ranging from $143 \%$ to $285 \%$. In a study of Besanko et al. (2005), the range was from $22 \%$ to $558 \%$, whereas the recent study by Pauwels (2007) found pass-through rates from $0 \%$ to $183 \%$. Therefore, the pass-through rate in our study is relatively high, but still comparable to those found in other studies.

\section{Actual profitability of the sales promotions}

The analysis computes the profitability of a sales promotion as the extra profit for the specific item due to the sales promotion, that is, the net increase in margin minus the costs of the sales promotion. The extra sales are actual sales minus baseline sales. "Baseline sales" are the sales that would have occurred at the regular price. We compute baseline sales by taking the average weekly sales over a period of 10 weeks: 5 weeks before and 5 weeks after the particular week, leaving out the highest and the lowest value, weeks with promotions in the category, and weeks with special days (e.g. the Christmas week). Tables 2 and 3 shows the profitability figures calculated in this way.

Table 2 shows that over all 86 sales promotions, the average profit per sales promotion is negative for the manufacturer $(-59)$, positive for the retailer $(+62)$, and marginally positive $(+3)$ for the channel as a whole. About one-third (35\%) of all sales promotions are profitable for the manufacturer whereas this stands at two-thirds (67\%) for the retailer. At the channel level, 47 sales promotions $(55 \%)$ are profitable, implying that the channel profit is 
Table 2 Profitability of the sales promotions in the database for the retailer and the manufacturer $(n=86)$. (Profits are in NLG-Dutch guilders)
Average profit per sales promotion

Number of profitable sales promotions

\begin{tabular}{lrl}
\hline Manufacturer & -59 & $30(35 \%)$ \\
Retailer & 62 & $58(67 \%)$ \\
Channel & 3 & $47(55 \%)$ \\
\hline
\end{tabular}

negative for almost half of the sales promotions. Only a small number, 16 out of 86 , or $19 \%$ of the sales promotions are profitable for both retailer and manufacturer (Table 3).

Next, we can compare these outcomes with figures in literature. The finding that $19 \%$ of the sales promotions are profitable for both manufacturers and retailers is close to the figure of $16 \%$, mentioned by Drèze and Bell (2003). Interestingly, in our study the manufacturer fares worse than the retailer, whereas Srinivasan et al. (2004) conclude the opposite. The fact that the present study takes into account the amount the manufacturer pays to the retailer as contributions for the flyers and other promotional activities (these numbers were available in the ECR dataset, but not in the Srinivasan et al. study) explains this difference. Otherwise, our study would also have concluded that the majority of the sales promotions are profitable for the manufacturer and not for the retailer. Altogether, the results confirm the bleak view regarding the profitability of sales promotions.

The computation here is for the direct effect of a sales promotion. The study could include indirect effects, for example cross-brand effects, accounting for the fact that a part of the extra sales may come at the cost of lower sales of other brands in the same category. This inclusion would only further deteriorate the profitability of the sales promotions. Including cross-period substitution (e.g., taking into account that the sales may be lower in the weeks after the sales because of stockpiling) would have the same effect. However, such effects are small for fresh products with a limited shelf life as we have here.

Potential profitability and evidence of double marginalization

Are there indications that the low profitability of these sales promotions is due to suboptimality caused by double marginalization? To answer this question, we compute the optimal sales promotions for the 86 cases. This requires a model for the relationship between the consumer discount price and sales, i.e. the discount response function. We test a linear model versus a power function. To determine the shape of the discount response function, we pool data from the various sales promotions. In order to make the cases commeasurable, we set the baseline sales at 100 for each case and then express the actual sales in the terms of the corresponding index number. We do the same for the price (regular price $=100$ ). In this way, we obtain data points for 86 sales promotions, with a number for the discount price and a number for sales for each sales promotion. Regression analyses, one for the linear model and one for the power model, result in a slightly better fit with the linear model $\left(\mathrm{R}^{2}\right.$ is 0.28 for the linear model and 0.27 for the power model). This finding is in agreement with other authors, for example, Bresnahan and Reiss (1985) who find linear retail demand curves (at least locally). The remainder of the analyses uses a linear relationship between consumer discount price and sales.

Next, we estimate a linear model for the relationship between price discount and sales for each individual sales promotion. The inputs are the baseline sales (at the regular price) and the actual sales (at the consumer discount price). With this information it is possible to estimate the parameter $\gamma$ of the discount response function (see Eq. A1.1) for each sales promotion. Subsequently, the study computes the optimal channel discount, $\mathrm{d}_{\mathrm{c}}{ }^{* *}$, (using Eq. 5), and the corresponding sales and profit. A comparison is then possible between the channel profit corresponding with the optimal consumer price discount and the actual channel profit.

Table 4 shows that the suboptimality of the channel is very serious indeed. Over all 86 cases, total channel profit for the actual sales promotion is only a tiny fraction (less than one percent) of the potential channel profit that is with all price discounts set at the optimal level (266 versus 31,914 guilders). The average actual profit per sales promotions is only three guilders (266/86), which is negligible. However, with channel-optimal discounts, the average profit per sales promotion increases by 368 to 371 guilders $(31,914 / 86)$.

Table 3 Numbers of profitable/nonprofitable sales promotions for the manufacturer and the retailer respectively

\begin{tabular}{llll}
\hline & Profitable for manufacturer $(\mathrm{M}+)$ & Not profitable for manufacturer $(\mathrm{M}-)$ & $\mathrm{n}$ \\
\hline Profitable for Retailer $(\mathrm{R}+)$ & 16 & 42 & $58(67 \%)$ \\
Not Profitable for Retailer $(\mathrm{R}-)$ & 14 & 14 & $28(33 \%)$ \\
& $30(35 \%)$ & $56(65 \%)$ & 86 \\
\hline
\end{tabular}


Table 4 Actual channel performance versus optimal channel performance (Numbers are in Dutch guilders)

\begin{tabular}{lcc}
\hline & Actual & Optimal \\
\hline $\mathrm{d}_{\mathrm{c}}$ (mean) & 0.37 & 0.45 \\
Channel profitability of sales promotions & 266 & 31,914 \\
Profitability per sales promotion & 3 & 371 \\
\hline
\end{tabular}

Sensitivity to production cost figures The results in Table 4 are based on a production cost figure of $70 \%$ of the regular selling price of the manufacturer to the retailer. As mentioned earlier, we have the actual production cost figures for 25 of the 86 sales promotions in our database. We analyzed these 25 separately and found that when we go from the actual to the channel-optimal sales promotion the improvement in profitability is on average 312 guilders per sales promotion. Although this is slightly lower, it is of the same order of magnitude as the increase (368) in Table 4 for all the sales promotions under the $70 \%$ production cost assumption. This robustness check confirms our conclusion that the discounts for the sales promotions in the database are not optimal.

What is behind this suboptimality? From Table 4 we conclude that, on average, the consumer discount, $\mathrm{d}_{\mathrm{c}}$, is too small (37 cents, compared to an optimal discount of 45 cents). This is in agreement with the conclusion in the analytical section of this paper that double marginalization leads to price discounts that are not deep enough.

To assess whether a discount is too low or too high, it is useful to consider the derivative of the profitability of the sales promotion with respect to the size of the discount. Therefore, this study computes that derivative for each sales promotion. This occurs for the channel discount, the manufacturer discount, and the retailer discount, respectively. The values of these derivatives refer to the situation of the actual discount (for the formulae, see Appendix 1).

Table 5 provides the outcomes. For example, the table shows that in 63 of 86 sales promotions, the derivative of channel profitability with respect to channel discount (= consumer discount) is positive. A positive number implies that channel profitability increases as consumer discount becomes larger. In other words, from a channel perspective, the majority ( 63 out of 86 , i.e. $73 \%$ ) of the actual consumer discounts are too small.

However, from the perspective of the manufacturer and the retailer the discounts are too large. In $97 \%$ of the cases ( 83 out of 86), the manufacturer would increase its profit by lowering its discount. For the retailer this is the case in $72 \%$ (62 out of 86) of the cases. Therefore, we have a clear-cut situation of double marginalization here: individual channel parties have an incentive to decrease their discounts whereas for a channel as a whole the discount should be larger.

Nash equilibrium As mentioned earlier, if the conditions for each sales promotion were the result of an ongoing dynamic adjustment process between the actors, theoretically, a Nash equilibrium would be the result. However, we do not expect this to occur very often in our dataset, because each sales promotion is unique and its conditions are typically determined in a "one-shot" interaction between the manufacturer and the retailer. When verifying this, we found that the actual discounts in our data are in agreement with the Nash equilibrium in $6 \%$ of the sales promotions. (Since exact equality is not likely, we concluded that a discount value is at the Nash equilibrium value if it is less than 5 cents removed from that value). The Nash equilibrium is typically a rest point from some dynamic adjustment process of a game that is played repeatedly (Mas-Colell et al. 1995, p 249). Since each sales promotion is a unique event that is played only once (not "the rest point of a dynamic adjustment process", Ibid $\mathrm{p}$ 249), it is not surprising that a Nash equilibrium does not occur very often in our data.

\section{Removing suboptimality by means of channel coordination}

\section{Existing approaches}

We first briefly discuss three approaches from literature that might be used for removing suboptimality in sales promotions.

Table 5 Conclusions about the discount from the channel, the manufacturer, and the retailer's point-of-view at the actual discount levels

\begin{tabular}{|c|c|c|c|c|c|}
\hline & & $>0$ & $<0$ & \# & Conclusion \\
\hline Channel & $\delta \Pi_{\mathrm{c}} / \delta \mathrm{d}_{\mathrm{c}}$ & $63^{\mathrm{a}}$ & 23 & 86 & Discount is too small \\
\hline Manufacturer & $\delta \Pi_{\mathrm{m}} / \delta \mathrm{d}_{\mathrm{m}}$ & 3 & 83 & 86 & Discount is too large \\
\hline Retailer & $\delta \Pi_{\mathrm{r}} / \delta \mathrm{d}_{\mathrm{r}}$ & 24 & 62 & 86 & Discount is too large \\
\hline
\end{tabular}

a) This means that for 63 sales promotions the derivative of the channel profitability of the sales promotion with respect to the channel discount is positive. 


\section{Two-step approach}

This approach consists of the following steps: (1) ensure that the consumer discount is set so that it maximizes channel profit; (2) make an agreement about the division of the profit generated by this channel-optimal sales promotion. The terms of this agreement depend on the relative power of the parties. One option is that the manufacturer receives all the benefits from moving to the channel optimum. At the other extreme, all these additional benefits go to the retailer. A solution receiving considerable attention from game theorists (Harsanyi 1956; Nash 1950; Zeuthen 1930) is that negotiations lead to an equal division of the additional profits; i.e., a 50/50 split of the benefits. The approach of first maximizing channel profit and then distributing benefits is conceptually simple, but its implementation requires a large degree of mutual trust. One option is to use a model, determine the optimal discount, compute the additional channel profit ex ante, and distribute this additional profit between the channel parties, before running the sales promotion. Another option is to measure the actual additional sales generated by the sales promotion afterwards and use this as a basis for the distribution of profits. Besides mutual trust, both options also require the separate transfer of money between parties, which is another disadvantage.

\section{Pricing schedules}

Ailawadi et al. (1999) propose to solve this problem of double marginalization by having the manufacturer design pricing schedules. A pricing schedule is a set of combinations of manufacturer selling prices and retail selling prices, designed so that the retailer finds it optimal to price at a level that maximizes total channel profit. This "leads" the retailer to the channel-optimal selling price. To make this operational, both the manufacturer and the retailer have to know the demand function. Otherwise, the manufacturer cannot devise a price schedule that will lead the retailer to the channel optimum, and the retailer cannot decide about its optimum. Second, a pricing schedule as proposed by Ailawadi et al. is not unique. Each schedule implies a certain allocation of the profit over manufacturer and retailer, and why would a retailer go along with a particular schedule? The manufacturer can only enforce this if it is very powerful in comparison to the retailer.

\section{Scan-back agreements}

This proposition is from Drèze and Bell (2003), whose study focuses on scan-back trade deals as instruments to address the problem of forward buying by retailers. When using scan-backs, the quantities that a retailer actually sells during a sales promotion are measured (using scanner data). Drèze and Bell show that a manufacturer can devise a "redesigned scan-back" agreement that makes the retailer slightly better off and the manufacturer strictly better off. The authors call this "win-win trade promotions". Such redesigned scanbacks typically involve deeper discounts and higher retail sales. Drèze and Bell's approach is in the same spirit of what we propose, but their redesigned scan-back agreement only deals with the forward buying problem. It does not eliminate the problem of double marginalization in sales promotions (Drèze and Bell 2003, p 35).

The proposed agreement: proportional discount sharing (PDS)

The new agreement proposed in this paper is proportional discount sharing (PDS) where the two channel partners contribute to the price discount in proportion to their original margins. If such an agreement is in force, a price discount decision by an individual channel party automatically leads to the channel optimum.

The original margin of the retailer is regular consumer price minus selling price of the manufacturer: (p-s) and the original margin of the manufacturer is selling price of the manufacturer minus production costs: (s-c). Therefore, a PDS agreement implies the following:

$\mathrm{d}_{\mathrm{r}} / \mathrm{d}_{\mathrm{m}}=(\mathrm{p}-\mathrm{c}) /(\mathrm{s}-\mathrm{c})$

Therefore, we have to prove that if the ratio of the discounts is in agreement with Eq. (8), channel coordination occurs.

If we define the parameter $\tau$, so that

$\mathrm{d}_{\mathrm{r}} / \mathrm{d}_{\mathrm{m}}=(\tau-1)$

(It is analytically easier to define this ratio as $(\tau-1)$ instead of $\tau$, but this is arbitrary)

Combining Eq. (9) with Eq. (A1.4)), results in:

$\Pi_{\mathrm{m}}=-\gamma \tau \mathrm{d}_{\mathrm{m}}\left(\mathrm{s}-\mathrm{c}-\mathrm{d}_{\mathrm{m}}\right)-\mathrm{Bd}_{\mathrm{m}}-\mathrm{FS}_{\mathrm{m}}$

Setting $\delta \Pi_{\mathrm{m}} / \delta \mathrm{d}_{\mathrm{m}}=0$ and solving for $\mathrm{d}_{\mathrm{m}}$, gives:

$\mathrm{d}_{\mathrm{m}} *=\mathrm{B} /(2 \gamma \tau)+(\mathrm{s}-\mathrm{c}) / 2$

Using Eq. (9), gives:

$\mathrm{d}_{\mathrm{r}}=(\tau-1)[\mathrm{B} /(2 \gamma \tau)+(\mathrm{s}-\mathrm{c}) / 2]$

Therefore:

$\left(\mathrm{d}_{\mathrm{m}} *+\mathrm{d}_{\mathrm{r}}\right)=\mathrm{B} /(2 \gamma)+\tau(\mathrm{s}-\mathrm{c}) / 2$

The left-hand side of Eq. (13) denotes the total channel discount if the manufacturer maximizes its profit, and the retailer's discount is linearly related to the manufacturer's discount according to Eq. (9). The question then is for what value of $\tau$ does this coincide with the overall channel optimum? 
If the PDS condition applies $\left[\mathrm{d}_{\mathrm{r}} / \mathrm{d}_{\mathrm{m}}=(\mathrm{p}-\mathrm{s}) /(\mathrm{s}-\mathrm{c})\right]$, $\tau=(\mathrm{p}-\mathrm{c}) /(\mathrm{s}-\mathrm{c})$. If we substitute this in Eq. (13), we get $\left(\mathrm{d}_{\mathrm{m}} *+\mathrm{d}_{\mathrm{r}}\right)=\mathrm{B} /(2 \gamma)+(\mathrm{p}-\mathrm{c}) / 2$.

The right-hand side of Eq. (14) is identical to the expression for the optimal consumer discount as given by Eq. (7). Therefore, this shows that if PDS applies, the discount that maximizes the manufacturer's profit also maximizes the profit of the channel. This analysis takes the perspective of the manufacturer, but taking the retailer's perspective produces the same result.

This analysis proves the proportional discount sharing (PDS) rule - allocating their contributions to the consumer price discount in proportion to their original margins aligns the profit maximization of the manufacturer, the retailer and the channel. Therefore, PDS coordinates the channel.

Jeuland and Shugan (1983, p 252) propose a general form for a mechanism for channel coordination, whereby the manufacturer receives fraction $k_{1}$ of channel profits plus a fixed amount $k_{2}$, while the retailer receives fraction (1 $\mathrm{k}_{1}$ ) minus the fixed amount $\mathrm{k}_{2}$. They implement their general principle for channel coordination, formulated above, as a quantity-discount-pricing schedule. However, it is straightforward to interpret PDS as an implementation of the general Jeuland and Shugan mechanism to sales promotions, with $\mathrm{k}_{1}=(\mathrm{s}-\mathrm{c}) /(\mathrm{p}-\mathrm{c})$ and $\mathrm{k}_{2}=0$. (In fact, $\mathrm{k}_{2}$ is not relevant here because it plays no role in the location of the optimum). This is another proof that PDS leads to channel coordination. In the empirical application, we show how this works for actual sales promotions.

In comparison to the other approaches, the implementation of PDS is very straightforward. It means simply allocating the consumer price discount between the channel partners in proportion to their margins before the discount. Of course, this information has to be available. If exact information is not available, for example about margins, the best possible estimates should be used. As regards to the size of the consumer discount, each of the two parties can make this decision separately or they decide jointly. Whoever has the most accurate market information is in the best position to do this. PDS does not require separate money transfer between parties, either model-based or scan-back-based. There is also an element of fairness in that the party with the largest margin also contributes most to the consumer discount.

\section{Application of PDS to the ECR data}

This study applies PDS to the 86 sales promotions of the ECR study. Compared to the actual sales promotion, the channel parties are never worse off with PDS and, in many cases, they are better off. Table 6 gives the improvements
Table 6 Effect of channel coordination through proportional discount sharing (PDS) (Numbers are in Dutch guilders)

\begin{tabular}{lccc}
\hline & \multicolumn{2}{l}{ Average profit per sales promotion } \\
\cline { 2 - 4 } & Actual & PDS & Improvement \\
\hline Manufacturer & -59 & 165 & 224 \\
Retailer & 62 & 206 & 144 \\
\hline
\end{tabular}

when PDS is used, compared to the actual sales promotions for the manufacturer and the retailer respectively.

Both parties benefit substantially from PDS. The situation is clearly win-win. The average improvement per sales promotion is somewhat larger for the manufacturer (224) than for the retailer (144). However, the amount per sales promotion shows considerable variation, and the difference between these two averages is not significant. This suggests that the PDS mechanism is not biased in that it does not systematically favor one of the two parties. This is also an attractive feature of PDS. These results demonstrate that PDS creates substantial profit improvements for both the manufacturer and the retailer by achieving channel coordination.

\section{Conclusions, managerial implications, and further research}

\section{Contribution}

The main contribution of this paper is to show the causes of suboptimal sales promotions and to propose an agreement, which produces a win-win situation for the manufacturer and the retailer. If manufacturers and retailers make their decisions regarding sales promotions from only the perspective of maximizing their own profit, then suboptimal sales promotions will be the result. In the paper, we have explained why this is the case with a theoretical model and we have demonstrated how this works out in practice with an empirical study. The implication is that sales promotions are less profitable than they could be. Therefore, this contributes to the low profitability of sales promotions observed in practice. We have also proposed an instrument to prevent this from happening: the proportional discount sharing agreement, which will coordinate the channel.

Managerial implications

There are clear benefits from agreements that bring about channel coordination for sales promotions, but perhaps sacrifices as well. Channel coordination may involve 
sharing information (e.g., about margins) with the other channel party, which they would not have shared otherwise, or giving up degrees of freedom (e.g., the possibility of adapting a consumer price discount at the last moment). Channel parties will only cooperate if they understand why this is in their own interest and how they can benefit (especially in the long run). This requires a considerable level of trust, as we will discuss below.

Most importantly, parties have to become aware of the channel coordination problem and its implications for the profitability of sales promotions. Although sales promotions are used intensively, many companies spend little effort on the analysis of the results and are often not aware of the low profitability. With the recent developments in IT and scanner data, this situation is improving. More seriously, it is unlikely that the representatives of manufacturers and retailers who negotiate about the conditions for sales promotions are aware of the double marginalization mechanism. Although it is not a problem if they do not know this term, they should at least have an intuitive feeling for the phenomenon and understand that by only looking at their own interest they may threaten the interest of the channel, and therefore indirectly jeopardize themselves. We hope that this paper contributes to the awareness of this phenomenon.

Any agreement for channel coordination in sales promotions is maintainable only if parties trust each other. Furthermore, they should take a long-term perspective. It is not about who gets what in one particular sales promotion, but about getting the best joint results from a series of sales promotions in which the parties work together. Representatives of practice make appeals for developing such joint promotion strategies (Jones 2004). The ECR (Efficient Consumer Response) movement also calls for joint strategies for efficient promotions. This paper provides a theoretical basis for these appeals and shows how much can be gained. Joint promotion strategies are also in agreement with the ideas about partnerships between distributors and manufacturers found in marketing literature (Anderson and Narus 1990). Within the vertical distribution channel, it is increasingly recognized that parties should work together and improve coordination (Achrol and Etzel 2003). Monitoring channel members, through the electronic transfer of information, is becoming more and more fashionable. High levels of data interchange (e.g., in ECR contexts) are transforming the nature of many channel relationships (Frazier 1999); it also helps to prevent cheating. Information sharing as a basis for joint decisionmaking in sales promotions is becoming more and more acceptable. The observation that scan-back agreements are increasingly replacing off-invoice allowances (Cannondale Associates 2000) illustrates this.

\section{Limitations}

The approach proposed in this paper will not completely solve the problem of the low profitability of sales promotions, but it can contribute to improving the results. Double marginalization is not the only cause of the low profitability of sales promotions. Several reasons exist why channel partners sometimes accept "leaky" sales promotions. Sometimes the primary goal of a sales promotion is to increase market share, and not the profit on the sales promotion itself. The long-term effect of sales promotions on market share is very limited, however (Srinivasan et al. 2000). A strategic motivation for accepting sales promotions even if they are not profitable can be the desire to maintain the relationship with a preferred channel partner. Alternatively, the purpose of a sales promotion may be to increase store traffic, where the profit is made on the sales of other products. Finally, there is the possibility of the prisoner dilemma, which occurs if individual channel members want to discontinue loss-making sales promotions, but maintain them because everyone else does so. However, we do not have the illusion that recognition of the double marginalization phenomenon makes all unprofitable sales promotions disappear. Nevertheless, knowing about the advantages of coordinating the channel and using the instruments discussed in this paper can help manufacturers and retailers to limit their losses. If full channel optimum is not possible in certain situations because of the type of considerations mentioned above, the theory and analysis presented in this paper at least make it possible to compute the costs (missed opportunities) implied by the suboptimality.

\section{Suggestions for future research}

The theory of this paper, in general, holds for all situations where manufacturers and retailers make decisions regarding sales promotions. The focus here is on the double marginalization mechanism in the context of price discounts. However, this mechanism plays a role in other marketing variables too. Whenever a channel party stops increasing its expenditures to make a sales promotion more attractive at the point where its marginal cost becomes equal to the own additional revenue (neglecting additional revenue generated elsewhere in the channel) sub-optimization occurs. This state implies that an individual channel party puts fewer resources in a sales promotion than what is optimal from a channel point of view. For example, a manufacturer has the incentive to lower product quality below the channel maximum level and to lower all other promotional decision variables at its disposal (Jeuland and Shugan 1983, p 247). This behavior can occur with any sales promotion instru- 
ment besides price discounts, for example with flyers, displays, premiums, etc. Extension of the current work to study the effect of lack of channel coordination on other sales promotion instruments is very welcome.

Furthermore, the empirical part of the paper is limited to one dataset. Additional empirical work, with other data, would be useful to further assess the amount of the loss in practice due to sales promotions lacking channel coordination. As we mentioned, it is not easy to obtain relevant data, and usually the cooperation of both the manufacturer and the retailer is required. We have examined the problem of double marginalization here for a particular food category and in a specific setting of "strong" manufacturers and retailers. It would be interesting to see if the same phenomenon occurs in other product categories and settings as concerns the relative power of the manufacturer and the retailer.

Other research needed is the development of multi-party decision support tools, which are useful to facilitate sales promotion agreements like PDS. Existing decision support tools for sales promotions are single-party tools that look from the perspective of one party, for example, the manufacturers' sales promotion calendar tool of SilvaRisso et al. (1999). With a multi-party decision support tool, one can simulate the effects of alternative discount options, and show their implications in terms of sales and profits, both for the retailer and the manufacturer. Multiparty decision support tools can also help manufacturers and retailers to understand the mechanism behind double marginalization.

Simple awareness of double marginalization by channel parties can help to alleviate the problem. In sales promotions, channel members are not only each other's adversaries (aiming for the largest possible part of the profit), but they also have to cooperate in order to make the joint profit as large as possible. We hope that this paper creates awareness of the potential benefits of cooperation in sales promotions and is helpful in finding and implementing solutions.

\section{Message to practice}

Our message to practice is the following. Use sales promotions that coordinate the channel if anyhow possible. We have shown how serious the losses can be if this is not the case and we propose a method how to achieve channel-coordinating sales promotions. Even if you are not able to apply channel-coordinating sales promotions, for example because of the relationship with your channel partner, it is still important to know how much potential profit is foregone at the channel level. This may help in negotiations with the channel partner to change the situation.
Appendix 1: Derivation of expressions used in the text

Let $\mathrm{q}\left(\mathrm{d}_{\mathrm{c}}\right)$ be the discount response function, i.e. relationship between the consumer price discount and the volume sold during a sales promotion $\left(\mathrm{p}_{\mathrm{d}}=\mathrm{p}-\mathrm{d}_{\mathrm{c}}\right)$.

We assume:

$\mathrm{q}\left(\mathrm{d}_{\mathrm{c}}\right)=\mathrm{B}-\gamma \mathrm{d}_{\mathrm{c}}$

where $\mathrm{B}=$ baseline sales (i.e. the sales level if there were no price discount) and $\gamma$ is parameter $(\gamma<0)$. For a precise description of the variables, see Appendix 1.

The baseline profit (i.e., without sales promotion) of the manufacturer is

$\mathrm{B}(\mathrm{s}-\mathrm{c})-\mathrm{F}_{\mathrm{m}}$

The manufacturer's profit with the price discount is:

$\left(\mathrm{B}-\gamma \mathrm{d}_{\mathrm{m}}-\gamma \mathrm{d}_{\mathrm{r}}\right)\left(\mathrm{s}-\mathrm{c}-\mathrm{d}_{\mathrm{m}}\right)-\mathrm{F}_{\mathrm{m}}-\mathrm{FS}_{\mathrm{m}}$

The manufacturer's profit due to the sales promotion, $\Pi_{m}$, is the difference between expression (A1.3) and expression (A1.2). After rearranging terms, we have:

$\Pi_{\mathrm{m}}=-\gamma\left(\mathrm{d}_{\mathrm{m}}+\mathrm{d}_{\mathrm{r}}\right)\left(\mathrm{s}-\mathrm{c}-\mathrm{d}_{\mathrm{m}}\right)-\mathrm{Bd}_{\mathrm{m}}-\mathrm{FS}_{\mathrm{m}}$

In the same way, the retailer profit due to the sales promotion is:

$$
\Pi_{\mathrm{r}}=-\gamma\left(\mathrm{d}_{\mathrm{m}}+\mathrm{d}_{\mathrm{r}}\right)\left(\mathrm{p}-\mathrm{s}-\mathrm{d}_{\mathrm{r}}\right)-\mathrm{Bd}_{\mathrm{r}}-\mathrm{FS}_{\mathrm{r}}
$$

When the manufacturer maximizes only his own (myopic) profit, the expression

$\delta \Pi_{\mathrm{m}} / \delta \mathrm{d}_{\mathrm{m}}=2 \gamma \mathrm{d}_{\mathrm{m}}-\gamma\left(\mathrm{s}-\mathrm{c}-\mathrm{d}_{\mathrm{r}}\right)-\mathrm{B}$

is set equal to zero. This results in:

$\mathrm{d}_{\mathrm{m}} *=\left(\mathrm{s}-\mathrm{c}-\mathrm{d}_{\mathrm{r}}\right) / 2+\mathrm{B} /(2 \gamma)$

However, if the manufacturer chooses $d_{m}$ so that the channel is optimized, he would also take into account the effect on the retailer's profit. He would now maximize the sum of the expressions (A1.4) and (A1.5). The result is:

$\mathrm{d}_{\mathrm{m}}{ }^{* *}=\left(\mathrm{s}-\mathrm{c}-\mathrm{d}_{\mathrm{r}}\right) / 2+\mathrm{B} /(2 \gamma)+\left(\mathrm{p}-\mathrm{s}-\mathrm{d}_{\mathrm{r}}\right) / 2$

The situation is symmetric, and we can also take the perspective of the retailer. When the retailer maximizes his own profit, the expression:

$\delta \Pi_{\mathrm{r}} / \delta \mathrm{d}_{\mathrm{r}}=-\gamma\left(\mathrm{p}-\mathrm{s}-\mathrm{d}_{\mathrm{m}}-2 \mathrm{~d}_{\mathrm{r}}\right)-\mathrm{B}$

is set equal to zero, and

$\mathrm{d}_{\mathrm{r}} *=\left(\mathrm{p}-\mathrm{s}-\mathrm{d}_{\mathrm{m}}\right) / 2+\mathrm{B} /(2 \gamma)$ 
If the retailer also took into account the profit effects for the manufacturer, he would maximize the sum of the expressions (A1.4) and (A1.5) and arrive at a discount of:

$\mathrm{d}_{\mathrm{r}} * *=\left(\mathrm{p}-\mathrm{s}-\mathrm{d}_{\mathrm{m}}\right) / 2+\mathrm{B} /(2 \gamma)+\left(\mathrm{s}-\mathrm{c}-\mathrm{d}_{\mathrm{m}}\right) / 2$

For the channel level we have:

$\Pi_{\mathrm{c}}=-\gamma \mathrm{d}_{\mathrm{c}}\left(\mathrm{p}-\mathrm{c}-\mathrm{d}_{\mathrm{c}}\right)-\mathrm{d}_{\mathrm{c}} \mathrm{B}-\mathrm{FS}_{\mathrm{r}}-\mathrm{FS}_{\mathrm{m}}$

Hence,

$\delta \Pi_{\mathrm{c}} / \delta \mathrm{d}_{\mathrm{c}}=-\gamma\left(\mathrm{p}-\mathrm{c}-2 \mathrm{~d}_{\mathrm{c}}\right)-\mathrm{B}$

Setting this expression equal to zero gives:

$\mathrm{d}_{\mathrm{c}} * *=(\mathrm{p}-\mathrm{c}) / 2+\mathrm{B} /(2 \gamma)$

Nash equilibrium

Given the retailer discount $d_{r}$, the manufacturer will set his discount according to Eq. A1.7:

$\mathrm{d}_{\mathrm{m}}^{*}=\left(\mathrm{s}-\mathrm{c}-\mathrm{d}_{\mathrm{r}}\right) / 2+\mathrm{B} /(2 \gamma)$

Next the retailer starting from this $\mathrm{d}_{\mathrm{m}}$ * sets (following Eq. A2.10) his discount at

$\mathrm{d}_{\mathrm{r}} *=\left(\mathrm{p}-\mathrm{s}-\mathrm{d}_{\mathrm{m}} *\right) / 2+\mathrm{B} /(2 \gamma)$

etc. etc.

These iterations eventually result in the equilibrium values:

$d_{m}(\infty)=\frac{1}{3} *\left(-p+3 s-2 c+\frac{2 B}{\gamma}\right)$

$d_{r}(\infty)=\frac{1}{3} *\left(2 p-3 s+c+\frac{B}{2 \gamma}\right)$

Open Access This article is distributed under the terms of the Creative Commons Attribution Noncommercial License which permits any noncommercial use, distribution, and reproduction in any medium, provided the original author(s) and source are credited.

\section{References}

Achenbaum A. A., \& Mitchel, K. F. (1987). Pulling away from push marketing. Harvard Business Review, (May-June), 38-40.

Achrol, R. S., \& Etzel, M. J. (2003). The structure of reseller goals and performance in marketing channels. Journal of the Academy of Marketing Science, 31(2), 146-163.

Ailawadi, K. L. (2001). The retail power-performance conundrum: What have we learned? Journal of Retailing, 77(3), 299-318.
Ailawadi, K. L., Farris, P., \& Shames, E. (1999). Trade promotions: Essential to selling through resellers. Sloan Management Review, Fall, 83-92.

Ailawadi, K. L., Harlam, B. A., César, J., \& Trounce, D. (2006). Promotion profitability for a retailer: The role of promotion, brand, category, and store characteristics. Journal of Marketing Research, 63, 518-535.

Anderson, J. C., \& Narus, J. A. (1990). A model of distributor firm and manufacturer firm working partnerships. Journal of Marketing, 54, 42-58.

Armstrong, M. K. (1991). Retail response to sales promotions: An incremental analysis of forward buying and retail promotion. Unpublished $\mathrm{PhD}$ dissertation, University of Texas at Dallas.

Besanko, D., Dubé, J. P., \& Gupta, S. (2005). Own-brand and crossbrand retail pass-through. Marketing Science, 24(1), 123-137.

Blattberg, R. C., \& Neslin, S. A. (1990). Sales promotion: Concepts, methods, and strategies. Englewood Cliffs: Prentice Hall.

Blattberg, R. C., Briesch, R., \& Fox, E. J. (1995). How promotions work. Marketing Science, 14(3), 122-132. part 2 of 2.

Bresnahan, T. F., \& Reiss, P. C. (1985). Dealer and manufacturer margins. Rand Journal of Economics, 16(2), 253-268.

Bucklin, R. E. (1987). Pass-through of manufacturer trade promotions by grocery retailers. Working paper, Stanford University, Oct 1987.

Cannondale Associates (2000). Trade promotion spending and merchandising industry study.

Chevalier, M., \& Curhan, R. C. (1976). Retail promotions as a function of trade promotions: A descriptive analysis. Sloan Management Review, 18(3), 19-32.

Choi, S. C. (1991). Price competition in a channel stucture with a common retailer. Marketing Science, 10(4), 271-296.

Coughlan, A. T., Anderson, E., Stern, L. W., \& El-Ansary, A. I. (2006). Marketing channels (7th ed.). Upper Saddle River: Prentice Hall.

Dekimpe, M. G., \& Hanssens, D. M. (1999). Sustained spending and persistent response: A new look at long-term marketing profitability. Journal of Marketing Research, 36, 397-412.

Drèze, X., \& Bell, D. R. (2003). Creating win-win trade promotions: Theory and empirical analysis of scan-back trade deals. Marketing Science, 22(1), 16-39.

Farris, P., \& Ailawadi, K. L. (1992). Retail power: Monster or mouse? Journal of Retailing, 68(4), 351-369.

FMI. (1993). Efficient consumer response. Washington DC: Food Marketing Institute.

Frazier, G. L. (1999). Organizing and managing channels of distribution. Journal of the Academy of Marketing Science, 27 (92), 226-240.

Gerstner, E., \& Hess, J. D. (1995). Pull promotion and channel coordination. Marketing Science, 14(1), 43-60.

Guadagni, P. M., \& Little, J. D. C. (1983). A logit model of brand choice calibrated on scanner data. Marketing Science, 2(no 3), 203-238.

Harsanyi, J. C. (1956). Approaches to the bargaining problem before and after the theory of games: A critical discussion of Zeuthen's, Hicks' and Nash's theories. Econometrica, 24(2), 144-157.

Ingene, C. A., \& Parry, M. E. (2004). Mathematical models of distribution channels. International series in quantitative marketing. New York: Kluwer Academic.

Ingene, C. A., \& Parry, M. E. (2007). Bilateral monopoly, identical distributors, and game-theoretic analyses of distribution channels. Journal of the Academy of Marketing Science, 35(4), 586-602.

Inman, J. J., McAlister, L., \& Hoyer, W. D. (1990). Promotion signal: Proxy for a price cut. Journal of Consumer Research, 17, 74-81.

Jeuland, A. P., \& Shugan, S. M. (1983). Managing channel profits. Marketing Science, 2(3), 239-272. 
Jones, C. (2004). The trade promotions Benchmark report: Pouring money into a leaky bucket (p. 41). Boston: The Aberdeen Group.

Kasulis, J. J., Morgan, F. W., Griffith, D. E., \& Kenderdine, J. M. (1999). Managing trade promotions in the context of market power. Journal of the Academy of Marketing Science, 27(3), 320-332.

Mas-Colell, A., Whinston, M. D., \& Green, J. R. (1995). Microeconomic theory. Oxford: Oxford University Press.

McGuire, T. W., \& Staelin, R. (1983). An industry equilibrium analysis of downstream vertical integration. Marketing Science, 2 (2), 161-191.

Moorthy, S. (2005). A general theory of pass-through in channels with category management and retail competition. Marketing Science, 24(12), 110-122.

Murry, J. P., \& Heide, J. B. (1998). Managing promotion program participation within manufacturer-retailer relationships. Journal of Marketing, 62(1), 58-68.

Nash, J. F. (1950). The bargaining problem. Econometrica, 18(2), $155-162$.

Neslin, S. A. (2002). Sales promotion. Cambridge: Marketing Science Institute.

Nijs, V., Dekimpe, M., Steenkamp, J. B. E. M., \& Hanssens, D. (2001). The category demand effects of price promotions. Marketing Science, 20(1), 1-22.

Orgel, D. (1996). Study urges trade promotion changes. Supermarket News, 46, 4-5.

Pauwels, K. (2007). How retailer and competitor decisions drive the long-term effectiveness of manufacturer promotions for fast-moving consumer goods. Journal of Retailing, 83(3), 297-308.

Rossiter, J. R., \& Bellman, S. (2005). Marketing communications, theory and applications. Frenchs Forest (Aus): Pearson Education Australia.

Silva-Risso, J. M., Bucklin, R. E., \& Morrison, D. G. (1999). A decision support system for planning manufacturers' sales promotion calendars. Marketing Science, 18(3), 274-300.
Spengler, J. J. (1950). Vertical integration and anti-trust policy. Journal of Political Economy, 58, 347-552.

Srinivasan, S., Popkowski Leszczyc, P. T. L., \& Bass, F. M. (2000). Market share response and competitive interaction: The Impact of temporary, evolving and structural changes in prices. International Journal of Research in Marketing, 12(4), 281-305.

Srinivasan, S., Pauwels, K., Hanssens, D. M., \& Dekimpe, M. (2004). Do promotions benefit manufacturers, retailers or both? Management Science, 50(5), 617-629.

Teunter, L. H. (2002). Analysis of sales promotion effects on household purchasing behavior. ERIM PhD Research Series in Management. Erasmus University Rotterdam, 262 p.

Trade Promotion. (2005). Spending and merchandising study. Wilton: Cannondale Associates.

Tyagi, R. K. (1999). A characterization of retail response to manufacturer trade deals. Journal of Marketing Research, 36, 510-516.

Urbany, J. E., Dickson, P., \& Sawyer, A. (2000). Insights into crossand within-store price search: Retailer estimates vs. consumer self-reports. Journal of Retailing, 76(2), 243-258.

Van Heerde, J., \& Neslin, S. A. (2008). Sales promotion models. In B. Wierenga (Ed.), Handbook of marketing decision models (pp. 107-162). New York: Springer Science + Business.

Van Waterschoot, W., \& van den Bulte, C. (1992). The 4P classification of the marketing mix revisited. Journal of Marketing, 56(4), 83-93.

Verstappen, C. D. G., van der Vorst, A. G. A. L., \& Wierenga, B. (1998). Cost, revenues and profits of sales promotion activities in a grocery channel. Management Report 1998-12, Rotterdam School of Management, Erasmus University Rotterdam.

Walters, R. G. (1989). An empirical investigation into retailer response to manufacturer trade promotions. Journal of Retailing, 65(2), 253-272.

Walzer, E. (1987). A challenge to the conventional wisdom. Progressive Grocer, (April), 4-5.

Zeuthen, F. (1930). Problems of Monopoly and Economic Welfare. London. 